\title{
Attempted Suicide Characteristics and Cerebrospinal Fluid Amine Metabolites in Depressed Inpatients
}

J. John Mann, M.D., Kevin M. Malone, M.D., M.R.C.Psych., John A. Sweeney, Ph.D., Richard P. Brown, M.D., Markku Linnoila, M.D., Ph.D., Barbara Stanley, Ph.D., and Michael Stanley, Ph.D.

Background: Serotonin abnormalities have been reported in the brain of suicide victims. Evidence of a serotonin deficiency in suicide attempters is less consistent. We hypothesized that a serotonin deficiency may be present in suicide attempters whose attempt behavior more closely approximates completed suicide. Method: Sixty-seven (67) drug-free depressed inpatients (46 suicide attempters, 21 nonattempters) underwent research clinical assessments and a lumbar puncture. Cerebrospinal fluid (CSF) monoamine metabolites were assayed. Degree of medical damage and intent of the most recent suicide attempt were rated. Results: CSF amine metabolites did not differentiate suicide attempters as a group from nonattempters. However, reduced serotonergic activity, as indicated by lower levels of CSF 5-hydroxyindoleacetic acid (5-HIAA) was associated with a history of planned suicide attempts and with suicide attempts that resulted in greater medical damage. Other monoamine metabolites did not correlate with seriousness of suicidal behavior, except for low CSF homovanillic acid and higher medical damage. No correlation was found with violent method. Conclusions: Planned and more medically damaging suicide attempts appear to be associated specifically with low serotonergic activity and, therefore, resemble completed suicide both behaviorally and biochemically. It remains to be determined whether low levels of CSF 5-HIAA can predict greater medical damage in future suicide attempts. (c) 1996 American College of Neuropsychopharmacology [Neuropsychopharmacology 15, 576-586]
KEY WORDS: Serotonin; Depression; Suicide; CSF amine metabolites

Lower levels of cerebrospinal fluid 5-hydroxyindoleacetic acid (CSF 5-HIAA) have been found in 11 of 16 studies of patients suffering from an episode of major

From the MHCRC for the Study of Suicidal Behavior (JJM, KMM RPB, BS, MS), Department of Psychiatry, College of Physicians and Surgeons, Columbia University, New York; the Department of Psychiatry (JAS), University of Pittsburgh, Pittsburgh, Pennsylvania; and the Laboratory of Clinical Studies (ML), National Institute on Alcohol Abuse and Alcoholism, Rockville, MD.

Address correspondence to: J. John Mann, M.D., Columbia University College of Physicians \& Surgeons, New York State Psychiatric Institute, 722 West 168th Street, Box 28, New York, NY 10032.

Received December 22, 1995; accepted April 23, 1996. depression who have made a suicide attempt compared with patients with depression who have not made a suicide attempt (Mann et al. 1992; Nordin 1988; Secunda et al. 1986; Roy et al. 1986; Roy-Byrne et al. 1983; Vestergaard et al. 1978; Banki and Arató 1983; Jones et al. 1990; Westenberg and Verhoeven 1988; Edman et al. 1986; Ågren and Niklasson 1986; Lopez-Ibor et al. 1985; van Praag 1982; Träskman et al. 1981; Palaniappan et al. 1983; Åsberg et al. 1976a and b). See Table 1 for a summary. Lower levels of CSF 5-HIAA in suicide attempters have also been reported by some, but not all studies of patients with personality disorders (Lidberg et al. 1985; Gardner et al. 1990; Träskman-Bendz et al. 1986; Brown et al. 1982, 1979) and schizophrenia (Cooper et al. 1992; Lemus et al. 1990; Pickar et al. 1986; Roy et al. 
1985; Ninan et al. 1984; van Praag 1983). Therefore, a pattern of low CSF 5-HIAA levels in suicide attempters compared with nonattempters appears present in multiple psychiatric disorders, suggesting that this biochemical difference is independent of psychiatric diagnosis and instead related to the suicidal behavior or a predisposition to suicidal acts. Such observations, taken together with findings in brain of suicide victims, have generated the serotonin deficiency hypothesis of suicidal behavior (Mann and Arango 1992). This hypothesis states that serotonergic activity mediates an inhibitory effect on suicidal behavior and, consequently, low serotonergic activity increases the probability of suicidal behavior.

This hypothesis is important, not only in furthering understanding of suicidal behavior, but also because of its potential diagnostic and treatment implications. It is, therefore, important to determine the basis for the lack of agreement with regards to an association between CSF 5-HIAA and suicidal behavior in depressed patients.
One possible reason why results differ among studies of depressed patients may lie in the composition of the patient populations. For example, negative results have generally been found in bipolar disorder (Vestergaard et al. 1978; Banki and Arató 1983; Secunda et al. 1986a; Roy-Byrne et al. 1983; Ågren 1980). An alternative explanation may be the type of suicidal behavior. Stengel and others (Stengel 1973) have described two broad categories of suicide attempts. The first is called failed suicide. This type of suicide attempt involves planning, a high lethality method, and a low chance of rescue. The second group involves a minimally planned suicide attempt using a low lethality method with a high probability of rescue. This latter type of suicide attempt has been variously termed including pseudocide, parasuicide, or suicide gesture (Lennard-Jones and Asher 1959; Stengel 1973). Few studies have directly examined what types of suicidal acts are related to low levels of CSF 5-HIAA.

Table 1. CSF 5-HIAA and Suicidal Behavior

\begin{tabular}{|c|c|c|c|}
\hline Study Impulsivity & Diagnosis & $\begin{array}{l}\text { Findings in CSF 5-HIAA } \\
\text { Attempters vs. Nonattempters }\end{array}$ & Violent Method \\
\hline Åsberg et al. 1976 & Depression & $\begin{array}{l}\downarrow 40 \% \text { of attempters had low CSF } 5 \text {-HIAA } \\
\text { vs } 15 \% \text { of nonattempters }\end{array}$ & $\begin{array}{l}\text { Violent method more common. } \\
\text { in low 5-HIAA group. No } \\
\text { data on impulsivity }\end{array}$ \\
\hline Vestergaard et al. 1978 & Depression & No difference in CSF 5-HIAA & \\
\hline Ågren 1980 & Depression & $\begin{array}{l}\text { Seriousness of intent of worst suicide } \\
\text { attempt--neg. correlation with CSF } \\
\text { 5-HIAA in unipolar but not bipolar } \\
\text { depression }\end{array}$ & \\
\hline Palaniappan et al. 1983 & Depression & CSF 5-HIAA $\downarrow$ in attempters & \\
\hline Träskman et al. 1981 & Depression & $\begin{array}{l}\text { CSF } 5 \text {-HIAA } \downarrow \text { in violent attempters and } \downarrow \\
\text { in nonviolent attempters }\end{array}$ & \\
\hline van Praag 1982 & Depression & CSF 5-HIAA $\downarrow$ (probenacid) in attempters & $\begin{array}{l}\text { No correlation with violence } \\
\text { of attempt }\end{array}$ \\
\hline Åsberg and Träskman 1981 & Depression & $\begin{array}{l}\text { Low CSF } 5 \text {-HIAA predicted } 22 \% \text { suicide } \\
\text { rate in } 1 \text { year }\end{array}$ & \\
\hline Roy-Byrne et al. 1983 & Depression & No difference in CSF 5-HIAA & \\
\hline Lopez-lbor et al. 1985 & Depression & $\begin{array}{l}\text { Low CSF 5-HIAA group had more } \\
\text { attempters }\end{array}$ & \\
\hline Ågren and Niklasson 1986 & Depression & CSF 5 -HIAA $\downarrow 12 \%$ in attempters $(p=.07)$ & \\
\hline Roy et al 1986 & Depression & $\begin{array}{l}\text { CSF } 5 \text {-HIAA } 22 \% \downarrow \text { in attempters vs. } \\
\text { nonattempters but nonsignificant }\end{array}$ & $\begin{array}{l}\text { No 5-HIAA differences due to } \\
\text { violent attempter method }\end{array}$ \\
\hline Secunda et al. 1986 & Depression & No diff in 5-HIAA & \\
\hline Edman et al. 1986 & Depression & CSF 5-HIAA $\downarrow$ in attempters & $\begin{array}{l}\text { Violent lower 5-HIAA and } \\
\text { faster skin conductance } \\
\text { habituation than nonviolent } \\
\text { attempters }\end{array}$ \\
\hline Peabody et al. 1987 & Depression & CSF 5-HIAA correlated with HAMD & $\begin{array}{l}\text { Also correlated with suicide } \\
\text { subscale }\end{array}$ \\
\hline Westenberg and Verhoeven 1988 & Depression & No difference & No differences \\
\hline Nordin 1988 & Depression & No correlation with suicidal thoughts & \\
\hline Jones et al. 1990 & Depressed elderly & CSF 5-HIAA $\downarrow$ in attempters & \\
\hline Banki and Arató 1983 & Mixed & $\begin{array}{l}\downarrow \text { in attempters; } \downarrow 37 \% \text { in violent vs } \\
\text { nonviolent attempters and vs } \\
\text { nonattempters }\end{array}$ & $\begin{array}{l}\text { Violent lower 5-HIAA than } \\
\text { nonviolent }\end{array}$ \\
\hline Mann et al. 1992 & Depression & $\begin{array}{l}\text { Only high planned suicide attempters had } \\
\text { lower CSF 5-HIAA }\end{array}$ & $\begin{array}{l}\text { No differences in violent } \\
\text { attempters }\end{array}$ \\
\hline
\end{tabular}


Some (Banki and Arató 1983; Edman et al. 1986; Åsberg et al. 1976b) but not most (Westenberg and Verhoeven 1988; van Praag 1982, 1983; Roy et al. 1986; Träskman et al. 1981) studies reported that violent suicide attempts characterize patients with low levels of CSF 5-HIAA. Alternatively, it has been hypothesized that impulsive suicide attempts may be associated with low CSF 5-HIAA. However, there are no data to directly support either of these suggestions (see Table 1). Impulsive, as opposed to premeditated, externally directed violence does appear to be associated with low CSF 5-HIAA in patients with personality disorders as well as in convicted murderers (Virkkunen et al. 1987; Brown et al. 1982, 1979; Linnoila et al. 1983; Lidberg et al. 1985), and CSF 5-HIAA is low in personality disorders characterized by impulsive aggression and suicidal behavior (Träskman-Bendz et al. 1986). Suicide attempters with major depression are more impulsive characterologically than nonattempters (Malone and Mann, unpublished data); this question needs to be studied further.

Impulsivity may be at least partly independent of a second aspect of suicidal behavior, namely the degree of planning or preparation. Completed suicides, as a group, are characterized by more planning of the suicidal act than suicide attempters as a group (Beck and Lester 1976; Beck and Steer 1989). At the same time, completed suicides appear to be associated with brain serotonin system abnormalities that are also independent of associated psychiatric diagnosis (Mann et al. 1996). Most, but not all studies have found serotonergic abnormalities that include reduced brainstem serotonin and / or 5-HIAA levels (Shaw et al. 1967; Pare et al. 1969; Moses and Robins 1975; Lloyd et al. 1974; Korpi et al. 1986; Cochran et al. 1976; Bourne et al. 1968; Beskow et al. 1976), a decreased number of serotonin transporter binding sites in prefrontal cortex in five out of 17 published studies, an increased number of $5-\mathrm{HT}_{2 \mathrm{~A}}$ receptors in prefrontal cortex in eight out of 13 published studies, increased $5-\mathrm{HT}_{1 \mathrm{~A}}$ receptors in entorhinal and prefrontal cortex in two out of three autoradiography studies and none out of three membrane binding studies, and decreased $5-\mathrm{HT}_{\mathrm{lD}}$ receptor sites in nondepressed suicides (Arranz et al. 1994); (see Mann et al. 1996 for a summary). Thus, an impresssive body of data supports a link between completed suicide and serotonergic abnormalities.

We hypothesized that suicide attempters most closely resembling suicide completers are more likely to have a similar abnormality in the serotonin system. We, therefore, studied the relationship between CSF 5-HIAA and the type of suicidal behavior, defined on the basis of the degree of medical damage inflicted and the level of suicidal intent and planning. A group of depressed inpatients who had recently attempted suicide were compared with depressed inpatients who had never attempted suicide. Preliminary results from a subgroup of this study population ( $n=34$ ) have been reported elsewhere addressing the relationship of degree of planning of a suicide attempt to CSF 5-HIAA (Mann et al. 1992). We found that highly planned suicide attempts were associated with lower CSF 5-HIAA (Mann et al. 1992). This study needed to be replicated. In the current study, we have extended the previous study by doubling the sample size, examining the relationship of CSF 5-HIAA to degree of medical damage; and studying the noradrenergic and dopaminergic systems to determine the biochemical specificity of the CSF correlates of suicidal behavior.

\section{METHODS}

Patients were included in the protocol after admission to a private university psychiatric hospital for evaluation and treatment of depression and subsequently having given written informed consent as required by the Institutional Review Board for Biomedical Research. The group comprised 67 inpatients. The consent rate for patients who were approached for the study was in excess of $70 \%$. Patients who refused the study did not differ from those included in the study on key variables of interest such as number and lethality of suicide attempts (Mann and Malone, unpublished data). The duration of the drug-free period was established by a combination of a drug screen, observation in hospital, and a history obtained from the patient's family and the referring physician. Patients had to be free for at least 14 days from drugs known to affect the serotonin system such as monoamine oxidase inhibitors, tricyclics, selective serotonin reuptake inhibitors, and serotonin agonists. The drug-free interval was longer for drugs with a long half-life such as fluoxetine (6 weeks) or oral antipsychotics (4 weeks). When the drug-free period was recorded, it was arbitrarily limited to 365 days. The group was drug-free for an average of 140 days (SD = 169). Suicide attempters who took an overdose included cases who took corrosives and other toxic agents without effect on the brain. The drug-free criteria were also met by the overdose group where the mean period off psychotropics prior to study was 93 days and did not differ from the other patients. Most of the suicide attempters $(n=46)$ had made a suicide attempt within 4 weeks prior to admission, with the interval between suicide attempt and lumbar puncture being 1 to 39 days (9.81 \pm 8.3 days). In all cases, patients were medically recovered from the effects of the suicide attempt by the time of the lumbar puncture. The number of lifetime suicide attempts per case was $2.7 \pm 2.2$ (range 1-10).

Diagnosis was established at a consensus conference according to DSM-III-R criteria (Spitzer et al. 1989) and based on results of a structured clinical interview (SADS) 
(Spitzer and Endicott 1978) and on independently carried out supplemental interviews by two research psychiatrists. Of the patients, 55 of 67 had a current major depressive episode (MDE), one was dysthymic with previous major depressive episodes, two had an adjustment reaction with depressed mood, three were schizoaffective or schizophreniform with pronounced depressed mood, and six had a combination of markedly depressed mood currently, borderline personality disorder (BPD) and a past history of major depression. The severity of depression on the 24-item Hamilton Depression Rating Scale (HAMD) (Hamilton 1960) was $31 \pm 8.1$ (with a range of (10 to 44 ). Clearly, most subjects were moderately to severely depressed. Of the patients, $16 \%$ were psychotic. Seven of the 55 patients with current MDE had bipolar I or II disorder.

Patients had a physical examination and routine laboratory screening tests to exclude neurologic disease and any other active physical disease that could affect their mental status or CSF 5-HIAA. Exclusion criteria included cardiac failure, renal or liver disease, malignancy, obstructive airways disease, endocrinopathies, and neurologic disorders.

The severity of depression was assessed by a 24 -item version of the HAMD (Hamilton 1960). The most recent suicide attempt was rated by the Suicide Intent Scale (SIS) (Beck et al. 1975) and the degree of medical damage by the Lethality Rating Scale (Beck et al. 1975). Suicide attempts were classified into nonviolent (drug overdose) or violent (gunshot, cutting, stabbing, jumping, or hanging). The suicide attempt method refers to the most recent suicide attempt, for which we had the most detailed data, and included drug overdose $(n=29)$, substance overdose $(n=1)$, shooting $(n=1)$, immolation $(n=1)$, cutting $(n=9)$, jumping $(n=1)$, hanging $(n=3)$ and other $(n=1)$. Thus, approximately two-thirds made a nonviolent attempt compared with one-third who made a violent attempt. The Beck Lethality Scale is scored from 0 to 8 , where no medical damage $=0$, and death $=8$. Thus scores ranged from 0 to 7 . Anchor points are provided for 0 to 8 and are individualized for eight different categories of methods of injury covering the major methods of suicide attempt. The scale is constructed to allow comparison of degree of medical damage across each of these eight categories of method of suicide attempt. Lifetime history of aggressive behavior was measured using the aggression history questionnaire developed by Brown and Goodwin (Brown et al. 1982, 1979). A categorical diagnosis of a BPD was based on DSM-III-R criteria, using a checklist (American Psychiatric Association Task Force 1987). Ratings of current psychopathology were based on the patient's clinical status over the 2 weeks prior to the sampling of CSF. Trait-related measures such as the aggression history questionnaire were carried out after stabilization of the patient's acute status. These latter ratings were almost always done after the CSF sampling and close to the timing of discharge.

Components of suicide intent were further defined based upon the results of our factor analysis (Mieczkowski et al. 1993) of the SIS (Beck et al. 1975). This factor analysis resulted in a two-factor solution. Factor 1, called lethal intent, contained items pertaining to the subjective lethality of the attempt. Factor 2 , called planning, contained items pertaining to the objective degree of planning for the attempt (see Table 2). Two subscale scores were generated based upon these results by summing the scores of items included within each factor.

The lumbar puncture was performed at about 0830 hours after the patient had been kept in bed at rest overnight and fasted from midnight. CSF was withdrawn from the L4-5 interspace while the patient was in the left decubitus position. After the removal of $1 \mathrm{ml}$ of CSF into the first sample tube, a further $15 \mathrm{ml}$ of CSF was collected in a second, single tube and immediately transferred on ice-water to be centrifuged at $4^{\circ} \mathrm{C}$. This 1 $5-\mathrm{ml}$ sample was then aliquoted into 1-ml samples for storage at $-70^{\circ} \mathrm{C}$ until assay. One of the $151-\mathrm{ml}$ samples was used for assay of monoamine metabolite levels.

CSF 5-hydroxyindoleacetic acid (5-HIAA), homovanillic acid (HVA), and 3-methoxy-4-hydroxyphenylglycol (MHPG) were assayed using our previously published method by high performance liquid chromatography (HPLC) with electrochemical detection (Scheinin et al. 1983). The within-run and between-run coefficients of variation of the assay method were less than $10 \%$. The level of sensitivity of the assay for 5-HIAA was 0.5 pmol/injection. All assays were done by laboratory staff blind to the clinical data. As previously reported, CSF 5-HIAA levels correlated with HVA levels $(r=0.6$, $p<.0005)$ and with MHPG $(r=0.25, p<.024)$. CSF HVA correlated with MHPG $(r=0.23, p<.036)$.

Cross-classification analyses were performed to test for significant differences in categorical demographic and clinical characteristics. Statistical comparisons between the nonattempters, high planning attempters,

Table 2. The Planning Subscale from a Factor Analysis of the Suicide Intent Scale

\begin{tabular}{|c|c|}
\hline $\begin{array}{l}\text { Item Number in } \\
\text { Original Scale }\end{array}$ & Description \\
\hline 1 & Isolation \\
\hline 2 & Timing \\
\hline 3 & $\begin{array}{l}\text { Precautions against discovery } \\
\text { or intervention }\end{array}$ \\
\hline 4 & $\begin{array}{l}\text { Acting to gain help during } \\
\text { or after attempt }\end{array}$ \\
\hline 5 & Final acts in anticipation of death \\
\hline 6 & Active preparation for attempt \\
\hline 7 & Suicide note \\
\hline 15 & Degree of premeditation \\
\hline
\end{tabular}


and low planning attempters were made using ANOVA. The Newman-Keuls post-hoc multiple comparison procedure was used to identify which groups were significantly different when a significant group effects was found by ANOVA. Results are reported as mean \pm standard deviation, and all probabilities are two-tailed. Inspection of the scatter plot of the suicide planning factor scores and levels of CSF amine metabolites suggested heterogeneity of variance of the CSF amine metabolites across levels of planning and medical damage. We therefore divided suicide attempters based on median splits into those characterized by high and low levels of suicide attempt planning according to scores on the suicide planning factor ( $\leqslant 9$ and $>9$, respectively): and, low and high levels of medical damage $(<3$ or $\geqslant 3$ score on Lethality Scale). Similarly, patients were divided into those with low and high levels of CSF 5 -HIAA $(\leqslant 100,>100 \mathrm{pmol} / \mathrm{ml})$, HVA $(\leqslant 190,>190$ $\mathrm{pmol} / \mathrm{ml})$, and MHPG $(\leqslant 43,>43 \mathrm{pmol} / \mathrm{ml})$. This approach allowed us to compare our results with some pivotal previously published studies that compared high and low CSF 5-HIAA groups (Träskman et al. 1981; Åsberg et al. 1976b).

\section{RESULTS}

The demographic and clinical characteristics of the patients (subdivided by lifetime history of no suicide attempt, and high versus low degree of medical damage) are shown in Table 3 . The overall group of patients was moderately to severely depressed as indicated by the mean 24-item HAMD score of $31.1 \pm 8.1$. There were no significant group differences in age, sex ratio, severity of depression, lifetime aggressivity, or rates of comorbid $\mathrm{BPD}$. The interval between the index suicide attempt and the lumbar puncture was $9.5 \pm 8.4$ days (range 1 to 39 ), and all were medically well at the time of the spinal tap. Of the suicide attempters, $65 \%$ took an overdose and the remainder used violent means. We assessed the relationship of CSF monoamine metabolite levels to the time since the last suicide attempt and found no correlation (CSF 5-HIAA: $r=0.07, n=42, p<.7$; CSF HVA: $r=$ 0.09, $n=41, p<.60$; CSF MHPG: $r=-0.07, n=39, p<.7$ ).

Males tended to have lower levels than females of CSF 5-HIAA (98.1 \pm 33.9 versus $113.3 \pm 33.1 \mathrm{pmol} / \mathrm{ml}$, $t=1.86, d f=65, p<.07)$, and CSF HVA $(170.7 \pm 82.6$ versus $211.2 \pm 85.7 \mathrm{pmol} / \mathrm{ml}, t=1.95, d f=64, p<.06$ ). There was no sex difference in CSF MHPG levels.

We initially compared mean levels of CSF 5-HIAA, HVA, and MHPG in all patients who had made a suicide attempt to patients who had never made a suicide attempt. No significant differences were found between attempters and nonattempters for CSF 5-HIAA (103.3 \pm 33.3 vs $112.0 \pm 35.7 ; p>.05)$, CSF HVA $(183.1 \pm 83.1$ vs $209.6 \pm 91.4, p>.05)$ or CSF MHPG $(44.1 \pm 12.4$ vs $44.1 \pm$ 8.4, $p>.05)$. A two-way ANOVA, including sex as an independent variable, identified no group or sex effect.

We then evaluated the type of suicide attempt. The degree of medical damage, the degree of planning for a suicide attempt, and whether or not violent method was used, were all considered. There was a significant positive correlation between planning and degree of medical damage $(r=0.47, n=46, p<.009)$. Based on a median split of the planning factor scores, planned suicide attempts resulted in greater medical damage than suicide attempts involving little planning $(4.1 \pm 0.9 \mathrm{vs}$ $2.5 \pm 2.3, t=3.44, d f=40, p<.001)$. High and low medical damage attempters did not differ in terms of severity of depression (Table 3). No significant linear correlations were observed between the CSF amine metabolites and the degree of medical damage. How-

Table 3. Demographics and Clinical Features of Populations

\begin{tabular}{lccc}
\hline & & \multicolumn{2}{c}{ Suicide Attempters } \\
\cline { 3 - 4 } Variables & Nonattempters & Low Medical Damage & High Medical Damage \\
\cline { 3 - 4 } & 21 & 28 & 21 \\
\hline $\begin{array}{c}\text { Number of patients } \\
\text { Age (years) }\end{array}$ & $49.3 \pm 14.7$ & $42.1 \pm 16.3$ & $39.0 \pm 16.6$ \\
$\begin{array}{l}\text { Male/Female ratio } \\
\text { Hamilton depression } \\
\text { scale score (24 item) }\end{array}$ & $11 / 10$ & $12 / 13$ & $9 / 12$ \\
$\begin{array}{c}\text { Life-time agression } \\
\text { history score }\end{array}$ & $30.0 \pm 6.9$ & $28.7 \pm 8.0$ & $32.0 \pm 9.1$ \\
$\begin{array}{c}\text { Percentage violent } \\
\text { attempters }\end{array}$ & $15.4 \pm 3.5$ & $16.5 \pm 4.7$ & $15.9 \pm 4.6$ \\
$\begin{array}{c}\text { Percentage comorbid } \\
\text { borderline P.D. }\end{array}$ & --- & $28 \%$ & $43 \%$ \\
\hline
\end{tabular}

\footnotetext{
${ }^{a}$ Note that for technical reasons, all patients did not have all three amine metabolites assayed, and so numbers may vary in analyses of individual metabolite results.
} 
ever, when patients were divided into those with high and low levels of CSF amine metabolites, and high and low medical damage (based on a median split of the Medical Damage Scale Score, $\geqslant 3$ and $<3$, respectively), it was observed that lower levels of CSF 5-HIAA were associated with more medical damage and higher levels of CSF 5-HIAA were associated with less medical damage (see Table 4). Lower CSF HVA also appeared associated with greater medical damage.

The relationship of high versus low planning suicide attempts to high versus low levels of CSF 5-HIAA, HVA, and MHPG was analyzed (Table 5). A significant difference was observed between low and high planned suicide attempter status for CSF 5-HIAA, but not HVA or MHPG (Table 5). Of patients with a history of highly planned suicide attempts, $73 \%$ had low CSF 5-HIAA compared with $37 \%$ of low planners $\left(X^{2}=4.27, d f=1\right.$, $p<.04$ ). The relationship of CSF 5-HIAA to level of planning was not linear. The rank order of mean levels of CSF 5-HIAA was high planners $<$ low planner attempters < nonattempters $(90.9 \pm 24.8$ vs $107.3 \pm 35.0$ and $112.0 \pm 35.7 \mathrm{pmol} / \mathrm{ml}$, respectively, $\mathrm{F}(2,64)=1.45$, $p<.24)$ and HVA $(153.8 \pm 57.4$ vs $191.5 \pm 87.9$ and $209.6 \pm 91.4 \mathrm{pmol} / \mathrm{ml}$, respectively; $\mathrm{F}(2,63)=1.44, p<$ .24); however the differences were not statistically significant. Low planning attempters had a mean level of CSF 5-HIAA closer to nonattempters than high planners. There was a trend for a greater proportion of high planners to have low CSF 5-HIAA compared with nonattempters $(p=.1)$, but no difference between low planning attempters and nonattempters $(p=.67)$. Mean CSF MHPG levels were $44 \mathrm{pmol} / \mathrm{ml}$ in all three groups. Considering gender in a two-way ANOVA did not alter the results. Factor 1 or subjective suicide intent did not correlate with any biochemical measures. In contrast to objective planning, the degree of subjective intent also did not correlate with degree of medical damage.

We compared violent and nonviolent suicide at-

Table 4. Relationship of Degree of Medical Damage Resulting from the Most Recent Suicide Attempt to Cerebrospinal Fluid Amine Metabolite Levels

\begin{tabular}{lcc}
\hline & $\begin{array}{c}\text { High }^{a} \text { Medical } \\
\text { Damage }\end{array}$ & $\begin{array}{c}\text { Low }^{a} \text { Medical } \\
\text { Damage }\end{array}$ \\
\hline High CSF 5-HIAA & 9 & 16 \\
Low CSF 5-HIAA & 16 & 5 \\
$\quad X^{2}=7.43, p=.0006$ & & \\
High CSF HVA & 5 & 11 \\
Low CSF HVA & 19 & 10 \\
$\quad X^{2}=4.86, p=.027$ & & \\
High CSF MHPG & 10 & 9 \\
Low CSF MHPG & 14 & 11 \\
$X^{2}=0.05, p=.82$ & & \\
\hline
\end{tabular}

${ }^{a}$ Based on scores of $\geqslant 3$ and $<3$ on the Lethality or Medical Damage Scale (Beck et al. 1975).
Table 5. Relationship of Objective Indices of Planning of Suicide Attempts to Cerebrospinal Fluid Monoamine Metabolite Levels

\begin{tabular}{lcc}
\hline & High Planners & Low Planners \\
\hline High CSF 5-HIAA & 3 & 22 \\
Low CSF 5-HIAA & 8 & 13 \\
$\quad X^{2}=4.27, p=.04$ & & \\
High CSF HVA & 2 & 14 \\
Low CSF HVA & 8 & 21 \\
$\quad X^{2}=1.36, p=.24$ & & \\
High CSF MHPG & 5 & 14 \\
Low CSF MHPG & 5 & \\
$X^{2}=0.25, p=.62$ & & \\
\hline
\end{tabular}

tempters in terms of higher or lower levels of CSF metabolites (see Table 6). No differences were found. Of the 16 subjects who carried out violent suicide attempts, $3(19 \%)$ fell into the high medical damage group, compared with $15(50 \%)$ of the 30 nonviolent attempts $\left(\mathrm{X}^{2}=\right.$ $4.28, p<.04)$. In this series of patients, the most lethal attempters involved drug overdoses.

\section{DISCUSSION}

This study examined systematically the relationship between dimensions of suicidal behavior in depressed patients and reduced levels of CSF 5-HIAA. We found that lower levels of CSF 5-HIAA were associated with first, suicide attempts resulting in more medical damage, and second, a greater degree of objective planning. No relationship was found with violent suicide method, subjective suicide intent, or the recency of the suicide attempt.

It was originally reported that CSF levels of 5-HIAA are distributed bimodally in depressed patients (Träskman et al. 1981; Åsberg et al. 1976a), and that the group with lower levels of CSF 5-HIAA are distinguished by a higher rate of past serious suicide attempts and a higher rate of future suicide (Åsberg and Träskman 1981).

Table 6. Relationship of Violent and Nonviolent Suicide Attempts to Cerebrospinal Fluid Amine Metabolite Levels

\begin{tabular}{lcc}
\hline & Violent Attempt & Nonviolent Attempt \\
\hline High CSF 5-HIAA & 11 & 14 \\
Low CSF 5-HIAA & 5 & 16 \\
$\quad \chi^{2}=2.05, p=.15$ & & \\
High CSF HVA & 5 & 11 \\
Low CSF HVA & 11 & 18 \\
$\quad X^{2}=0.20, p=.65$ & & 10 \\
High CSF MHPG & 9 & 19 \\
Low CSF MHPG & 6 & \\
$\quad X^{2}=2.61, p=.11$ & & \\
\hline
\end{tabular}


Since that report, many other studies have been published (Table 1) examining the relationship of CSF 5-HIAA to suicidal behavior in depressed patients and other psychiatric populations. Eleven previous studies (see Table 1) found lower levels of CSF 5-HIAA in patients with a major depressive disorder who had also carried out a suicide attempt compared to depressed patients who had not attempted suicide. Five studies did not find lower CSF 5-HIAA in suicide attempters.

We found that a history of a recent suicide attempt resulting in a greater degree of medical damage is associated with lower levels of CSF 5-HIAA, relative to a suicide attempt involving less medical damage or no history of a suicide attempt. The degree of medical damage was defined a priori on the basis of a median split of the scores on the Lethality Scale, and that split turned out to separate those requiring hospitalization for medical treatment from those not requiring admission to hospital. Because medical damage is a dimension that distinguishes completed suicide from failed suicide, and failed suicide from parasuicide, its relationship to low CSF 5-HIAA is of great interest. Previous studies of CSF 5-HIAA have not quantified the degree of medical damage, so direct comparison with our results is difficult. However, we recently found that the prolactin response to serotonin release by fenfluramine was blunted in a totally new group of patients with a current major depression and a past history of a high suicide attempt resulting in high medical damage (using the same cut-off score on the Medical Damage Scale as in this study) compared with a group of depressed patients who had made only low medical damage suicide attempts (Malone et al. 1995). That study offers powerful evidence in support of the current study's results, because it used a different method for assessing the serotonin system and involved a different group of patients.

The question exists as to whether the CSF 5-HIAA levels were affected by the degree of medical damage. The lack of correlation between CSF 5-HIAA levels and the time interval separating the attempt and the lumbar puncture, together with the drug-free interval, and the fact that all patients were medically well at the time of the lumbar puncture, suggests that the CSF 5-HIAA level was not a consequence of the suicide attempt or residual drug effects. A prospective study will be better able to address this question.

Another possible reason for lack of agreement in the literature may be the type of affective disorder included in the study population. Three of the five studies that did not find reduced CSF 5-HIAA levels in depressed patients who attempted suicide had included a significant number with bipolar disorder (Secunda et al. 1986; Vestergaard et al. 1978; Roy-Byrne et al. 1983). One study found lower CSF 5-HIAA levels in association with suicidal behavior in unipolar but not in bipo- lar depressed patients (Ågren 1980b). However, a second study where the depressed population comprised about $50 \%$ bipolar cases did find reduced CSF 5-HIAA in the attempters (Banki and Arató 1983). In our study, only $12 \%$ had a bipolar disorder, and yet we did not find lower levels of CSF 5-HIAA when all types of suicide attempts were considered. Moreover, disagreement is not limited to studies of depression, because it also occurs in studies of schizophrenia. Thus, it appears that diagnostic group or subgroup may not be a significant factor.

Another aspect of the type of suicidal act that may relate to low CSF 5-HIAA is the degree of planning. We found that more planning was associated with lower CSF 5-HIAA. It should be noted that planning and impulsivity are not opposites. The decision to act on a careful plan may be impulsive. Previous studies have not quantified either planning or impulsivity (see Table 1), so their relationship to CSF 5-HIAA has been hitherto unclear. Based on extrapolations from studies of externally directed aggression, suggesting that it is impulsive aggression that correlates with low CSF 5-HIAA (Linnoila et al. 1983; Lidberg et al. 1985; Virkkunen et al. $1987,1989 a, b)$, it may be presumed that impulsivity is greater in suicide attempters and, if so, impulsivity would be hypothesized to be negatively correlated with CSF 5-HIAA. Future studies of suicide attempters should quantitate impulsivity to determine whether this relationship is present in depressed suicide attempters.

In a pilot study involving half the subjects in this study, we found the same results as in this study, namely that only depressed patients with a history of a well-planned suicide attempt had lower CSF 5-HIAA than nonattempters (Mann et al. 1992). It has been reported (Beck et al. 1974a) that Beck SIS scores are higher in patients who complete suicide compared with patients who have attempted suicide, and this scale assigns higher scores to planning. Moreover, SIS scores are higher in patients who reattempt suicide in the future (Beck et al. 1974a, b) and in those who ultimately complete suicide (Beck and Steer 1989). Because degree of planning and premeditation are associated with greater medical damage (Pallis and Sainsbury 1976), from a behavioral standpoint, suicide attempters who plan suicide attempts resemble completed suicides. Moreover, it is the lethality of a suicide attempt that ultimately distinguishes a completed suicide from a failed suicide attempt or gesture. Thus, our findings and other studies indicate that highly planned, high lethality suicide attempters resemble suicide completers behaviorally.

Several studies (see Mann et al. 1996 for a review) have reported lower levels of serotonin and/or 5-HIAA in the brainstem of suicide victims compared with controls (Shaw et al. 1967; Pare et al. 1969; Moses and Robins 1975; Lloyd et al. 1974; Korpi et al. 1986; Cochran et 
al. 1976; Bourne et al. 1968; Beskow et al. 1976). Levels of 5-HIAA in frontal cortex correlate with CSF levels at postmortem (Stanley et al. 1985), indicating that CSF levels may reflect neuronal activity in relevant brain areas. Changes involving multiple serotonin receptors (serotonin transporter, $5-\mathrm{HT}_{2 \mathrm{~A}}$ and $5-\mathrm{HT}_{1 \mathrm{~A}}$ ) have also been found by some, but not all, studies in the brain of suicide victims (Arango et al. 1990; Stanley and Mann 1983; Arango and Mann 1992; Mann et al. 1989; Paul et al. 1984; Stanley et al. 1982) (see Mann et al. 1996 for a review). These findings in suicide completers appear to be independent of diagnosis. Therefore, although our study was largely confined to depressed patients, the findings suggest that a relationship exists between suicide completers and a subgroup of suicide attempters based on the behavioral dimension of suicide planning and the biological dimension of altered serotonergic activity. A category of failed suicide has been proposed (Beck et al. 1975; Stengel 1973) on the basis of similarities in the pattern of the suicidal behavior, namely use of a highly lethal method, minimization of the chances of rescue, and planning the attempt. On the basis of our CSF results, and our observation that greater planning is associated with more severe medical damage, failed suicides appear to be related to completed suicide not only in terms of behavioral aspects but also in biological measures of serotonin function.

It has also been hypothesized that the dimension of the suicidal behavior related to low CSF 5-HIAA is the degree of violence of the attempt as opposed to some other aspect of suicidal behavior such as suicidal intent. We did not find such a relationship. Our results are supported by the literature. Only three out of eight studies with available data reported that violent suicide attempts are associated with lower levels of CSF 5-HIAA (see Table 1). In agreement with our findings in suicide attempters, no relationship has been found between serotonin indices in the brain of suicide victims using violent as opposed to nonviolent suicide methods (Arango and Mann 1992). Therefore, the weight of the evidence is against this hypothesis. We have previously reported (Marzuk et al. 1992) that availability of method is a major factor determining choice of suicide method. Thus, selection of a violent method for suicide does not appear to be biologically determined, but instead may be dependent on the availability of specific methods, for example guns compared with pills.

With regard to suicidal behavior and CSF levels of HVA or MHPG, no consistent pattern has emerged in the literature. We found low CSF HVA was more frequent in association with high medical damage suicide attempts. We did not find an association between low CSF HVA and degree of planning. Some, but not all, studies report lower levels of CSF HVA in attempters (Ågren 1980a; Träskman-Bendz et al. 1986; Roy et al. 1986; Secunda et al. 1986a; Träskman et al. 1981; Ågren 1980a). There is also disagreement as to whether this relationship holds true only for major depressive disorder (Träskman et al. 1981) or whether it is also present in other diagnostic groups (Roy et al. 1986; Ågren 1980b). Thus, both our findings, and those in the literature, are less persuasive of a relationship between CSF HVA and suicidal behavior compared with the evidence for CSF 5-HIAA. CSF MHPG appears to have a unimodal distribution in affective disorders with levels tending to be elevated relative to controls (Koslow et al. 1983). One study found a complex relationship between CSF MHPG and suicidal behavior (Ågren 1980a,b). However, our study found no correlation. Unlike CSF 5-HIAA, we found that CSF MHPG did not have statistically significant relationships with either degree of medical damage or planning of the suicide acts, indicating a biochemical specificity for this biobehavioral correlation. This conclusion is supported by a recent report (Nordström et al. 1995) that CSF MHPG and HVA did not predict future suicide in a sample where low CSF 5-HIAA was associated with an increased suicide rate, 1 year after study.

In conclusion, we found that lower CSF 5-HIAA was associated with recent suicide attempt behavior characterized by greater planning and resulting in more medical damage. Given the genetic regulation of levels of CSF 5-HIAA (Higley et al. 1993; Oxenstierna et al. 1986), its stability over time (Hildebrand et al. 1990; Menachem et al. 1989), this test may have potential for not only predicting future suicide (Nordström et al. 1994; Träskman et al. 1981) and suicide attempts (Cooper et al. 1992; Roy et al. 1989), but also the seriousness of the attempt. Studies should be carried out to determine whether CSF 5-HIAA correlates with seriousness of suicidal behavior at a point remote in time from testing. If so, it may represent a measure of vulnerability for more lethal suicide attempts. Identification of such high risk patients is an essential step in order that treatment intervention can be targeted at the most appropriate population for the purpose of efficacy studies that are almost totally lacking in suicidal patients.

\section{ACKNOWLEDGMENTS}

A pilot report on part of this patient sample appeared in Mann et al. 1992): Relationship between central and peripheral serotonin indexes in depressed and suicidal psychiatric inpatients. Arch. Gen. Psychiatry 49:442-446. Technical assistance was provided by Mark Stipedick and Anne Peters. Assistance with patient recruitment and assessments was provided by Cathy Raduns, B.A., Susan Evans, R.N., Katherine S. Johnson, R.N., and Renee Azima Heller, M.A. Shuhua Li, Ph.D, and Elizabeth M. Corbitt, Ph.D, assisted with some statistical analyses. Ms. Irene Díaz expertly typed the manuscript. This work was supported by MH46745, MH40048, and MH48514. This article is dedicated to the memory of our dear scientific colleague and 
friend, Dr. Michael Stanley, whose untimely death deprived the scientific community of one of its most creative investigators.

\section{REFERENCES}

Ågren H (1980a): Symptom patterns in unipolar and bipolar depression correlating with monoamine metabolites in the cerebrospinal fluid. I. General patterns. Psychiatry Res 3:211-223

Ågren H (1980b): Symptom patterns in unipolar and bipolar depression correlating with monoamine metabolites in the cerebrospinal fluid. II. Suicide. Psychiatry Res 3:225236

Ågren H, Niklasson F (1986): Suicidal potential in depression: Focus on CSF monoamine and purine metabolites. Psychopharmacol Bull 22(3):656-660

American Psychiatric Association Task Force (1987): Diagnostic and Statistical Manual of Mental Disorders (DMS-III-R). Washington, DC: APA Press

Arango V, Ernsberger P, Marzuk PM, Chen J-S, Tierney H, Stanley M, Reis DJ, Mann JJ (1990): Autoradiographic demonstration of increased serotonin $5-\mathrm{HT}_{2}$ and $\beta$-adrenergic receptor binding sites in the brain of suicide victims. Arch Gen Psychiatry 47:1038-1047

Arango V, Mann JJ (1992): Relevance of serotonergic postmortem studies to suicidal behavior. Int Rev Psychiatry $4: 131-140$

Arranz B, Eriksson A, Mellerup E, Plenge P, Marcusson J (1994): Brain 5- $\mathrm{HT}_{1 \mathrm{~A}}, 5-\mathrm{HT}_{1 \mathrm{D}}$, and $5-\mathrm{HT}_{2}$ receptors in suicide victims. Biol Psychiatry 35:457-463

Åsberg M, Thorén P, Träskman L, Bertilsson L, Ringberger V (1976a): "Serotonin depression"-A biochemical subgroup within the affective disorders? Science 191:478480

Åsberg M, Träskman L, Thorén P (1976b): 5-HIAA in the cerebrospinal fluid. A biochemical suicide predictor? Arch Gen Psychiatry 33:1193-1197

Åsberg M, Träskman L (1981): Studies of CSF-5-HIAA in depression and suicidal behavior. Adv Exp Med Biol 133:739-752

Banki CM, Arató M (1983): Amine metabolites and neuroendocrine responses related to depression and suicide. J Affect Disord 5:223-232

Beck A, Schuyler D, Herman J (1974a): Development of suicidal intent scales. In Beck A, Resnick K, Letierri D (eds), The Prediction of Suicide. Bowie, MD, Charles Press

Beck RW, Morris JB, Beck AT (1974b): Cross-validation of the suicidal intent scale. Psychol Rep 34:445-446

Beck AT, Beck R, Kovacs M (1975): Classification of suicidal behaviors. I. Quantifying intent and medical lethality. Am J Psychiatry 132(3):285-287

Beck AT, Lester D (1976): Components of suicidal intent in completed and attempted suicides. J Psychol 92:35-38

Beck AT, Steer RA (1989): Clinical predictors of eventual suicide: A 5- to 10-year prospective study of suicide attempters. J Affect Disord 17:203-209

Beskow J, Gottfries CG, Roos BE, Winblad B. (1976): Deter- mination of monoamine and monoamine metabolites in the human brain: Post mortem studies in a group of suicides and in a control group. Acta Psychiatr Scand 53:7-20

Bourne HR, Bunney WEJ, Colburn RW, Davis JM, Shaw DM, Coppen AJ (1968): Noradrenaline, 5-hydroxytryptamine, and 5-hydroxyindoleacetic acid in hindbrains of suicidal patients. Lancet ii:805-808

Brown GL, Ebert MH, Goyer PF, Jimersom DC, Klein WJ, Bunney WEJ, Goodwin FK (1982): Aggression, suicide and serotonin: Relationships to CSF amine metabolites. Am J Psychiatry 139:741-746

Brown GL, Goodwin FK, Ballenger JC, Goyer PF, Major LF (1979): Aggression in human correlates with cerebrospinal fluid amine metabolites. Psychiatry Res 1:131-139

Cochran E, Robins E, Grote S (1976): Regional serotonin levels in brain: A comparison of depressive suicides and alcoholic suicides with controls. Biol Psychiatry 11:283294

Cooper SJ, Kelly CB, King DJ (1992): 5-Hydroxyindoleacetic acid in cerebrospinal fluid and prediction of suicidal behaviour in schizophrenia. Lancet 340:940-941

Edman G, Åsberg M, Levander S, Schalling D (1986): Skin conductance habituation and cerebrospinal fluid 5-hydroxyindoleacetic acid in suicidal patients. Arch Gen Psychiatry 43:586-592

Gardner DL, Lucas PB, Cowdry RW (1990): CSF metabolites in borderline personality disorder compared with normal controls. Biol Psychiatry 28:247-254

Hamilton M (1960): A rating scale for depression. J Neurol Neurosurg Psychiatry 23:56-62

Higley JD, Thompson WW, Champoux M, Goldman D, Hasert MF, Kraemer GW, Scanlan JM, Suomi SJ, Linnoila M (1993): Paternal and maternal genetic and environmental contributions to cerebrospinal fluid monoamine metabolites in Rhesus monkeys (Macaca mulatta). Arch Gen Psychiatry 50:615-623

Hildebrand I, Bourgeois F, Buyse M, Przedborski S, Goldman S (1990): Reproducibility of monoamine metabolite measurements in human cerebrospinal fluid. Acta Neurol Scand $81: 427-430$

Jones JS, Stanley B, Mann JJ, Frances AJ, Guido JR, Träskman-Bendz L, Winchel R, Brown RP, Stanley M (1990): CSF 5-HIAA and HVA concentrations in elderly depressed patients who attempted suicide. Am J Psychiatry 147:1225-1227

Korpi ER, Kleinman J, Goodman SI, Phillips I, DeLisi LE, Linnoila M, Wyatt RJ (1986): Serotonin and 5-hydroxyindoleacetic acid in brains of suicide victims. Comparison in chronic schizophrenic patients with suicide as cause of death. Arch Gen Psychiatry 43:594-600

Koslow SH, Maas JW, Bowden CL, David JM, Hanin I, Javaid J (1983): CSF and urinary biogenic amines and metabolism in depression and mania. A controlled univariate analysis. Arch Gen Psychiatry 40:999-1010

Lemus CZ, Lieberman JA, Johns CA, Pollack S, Bookstein P, Cooper TB (1990): CSF 5-hydroxyindoleacetic acid levels and suicide attempts in schizophrenia. Biol Psychiatry 27:926-929

Lennard-Jones JE, Asher R (1959): Why do they do it? A study of pseudocide. Lancet i:1138-1140 
Lidberg L, Tuck JR, Åsberg M, Scalia Tomba GP, Bertilsson L (1985): Homicide, suicide and CSF 5-HIAA. Acta Psychiatr Scand 71:230-236

Linnoila M, Virkkunen M, Scheinin M, Nuutila A, Rimond R, Goodwin FK (1983): Low cerebrospinal fluid 5-hydroxyindoleacetic acid concentration differentiates impulsive from non-impulsive violent behavior. Life Sci $33: 2609-2614$

Lloyd KG, Farley IJ, Deck JHN, Hornykiewicz O (1974): Serotonin and 5-hydroxyindoleacetic acid in discrete areas of the brainstem of suicide victims and control patients. Adv Biochem Psychopharmacol 11:387-397

Lopez-Ibor JJ, Saiz-Ruiz R, Perez de los Cobos JC (1985): Biological correlations of suicide and aggressivity in major depressions (with melancholia): 5-hydroxyindoleacetic acid and cortisol in cerebral spinal fluid, dexamethasone suppression test and therapeutic response to 5-hydroxytryptophan. Neuropsychobiology 14:67-74

Malone KM, Corbitt EM, Li S-H, Mann JJ (1995): Prolactin response to fenfluramine and suicide attempt lethality in major depression. Br J Psychiatry 168:324-329

Mann JJ, Arango V (1992): Integration of neurobiology and psychopathology in a unified model of suicidal behavior. J Clin Psychopharmacol 12(2):2S-7S

Mann JJ, Arango V, Marzuk PM, Theccanat S, Reis DJ (1989): Evidence for the 5-HT hypothesis of suicide: A review of post-mortem studies. Br J Psychiatry 155(Suppl 8):7-14

Mann JJ, McBride PA, Brown RP, Linnoila M, Leon AC, DeMeo MD, Mieczkowski TA, Myers JE, Stanley M (1992): Relationship between central and peripheral serotonin indexes in depressed and suicidal psychiatric inpatients. Arch Gen Psychiatry 49(6):442-446

Mann JJ, Underwood MD, Arango V (1996): Postmortem studies of suicide victims. In Watson SJ (ed), Biology of Schizophrenia and Affective Disease, ed 1. Washington, DC, American Psychiatric Press, pp. 197-220

Marzuk PM, Leon AC, Tardiff K, Morgan EB, Stajic M, Mann JJ (1992): The effect of access to lethal methods of injury on suicide rates. Arch Gen Psychiatry 49:451-458

Menachem BE, Persson L, Schechter PI, Haegele KD, Huebert N, Hardenberg J (1989): Cerebrospinal fluid parameters in healthy volunteers during serial lumbar punctures. J Neurochem 52:632-635

Mieczkowski TA, Sweeney JA, Haas GL, Mann JJ, Brown RP, Junker B (1993): Factor composition of the suicide intent scale. Suicide Life Threat Behav 23:37-45

Moses SG, Robins E (1975): Regional distribution of norepinephrine and dopamine in brains of depressive suicides and alcoholic suicides. Psychopharmacol Commun 1: $327-337$

Ninan PT, van Kammen DP, Scheinin M, Linnoila M, Bunney WEJ, Goodwin FK (1984): CSF 5-hydroxyindoleacetic acid levels in suicidal schizophrenic patients. Am J Psychiatry 141:566-569

Nordin C (1988): Relationships between clinical symptoms and monoamine metabolite concentrations in biochemically defined subgroups of depressed patients. Acta Psychiatr Scand 78:720-729

Nordström AL, Farde L, Nyberg S, Karlsson P, Halldin C, Sedvall $G$ (1995): $D_{1}, D_{2}$, and 5- $\mathrm{HT}_{2}$ receptor occupancy in relation to clozapine serum concentration: A PET study of schizophrenic patients. Am J Psychiatry 152: 1444-1449

Nordström P, Samuelsson M, Asberg M, Träskman-Bendz L, Aberg-Wistedt A, Nordin C, Bertilsson L (1994): CSF 5-HIAA predicts suicide risk after attempted suicide. Suicide Life Threat Behav 24:1-9

Oxenstierna G, Edman G, Iselius L, Oreland L, Ross SB, Sedvall $G$ (1986): Concentrations of monoamine metabolites in the cerebrospinal fluid of twins and unrelated individuals. A genetic study. J Psychiatr Res 20:19-29

Palaniappan V, Ramachandran V, Somasundaram O (1983): Suicidal ideation and biogenic amines in depression. Indian J Psychiatry 25(4):286-292

Pallis DJ, Sainsbury P (1976): The value of assessing intent in attempted suicide. Psychol Med 6:487-492

Pare CMB, Yeung DPH, Price K, Stacey RS (1969): 5-Hydroxytryptamine, noradrenaline, and dopamine in brainstem, hypothalamus, and caudate nucleus of controls and of patients committing suicide by coal-gas poisoning. Lancet ii:133-135

Paul SM, Rehavi M, Skolnick P, Goodwin FK (1984): High affinity binding of antidepressants to a biogenic amine transport site in human brain and platelet; studies in depression. In Post RM, Bellinger CJ (eds), Neurobiology of Mood Disorders. Baltimore, MD, Williams and Wilkins, pp. 846-853

Pickar D, Roy A, Breier A, Doran A, Wolkowitz O, Colison J, Ågren H (1986): Suicide and aggression in schizophrenia. Neurobiologic correlates. Ann NY Acad Sci 487: 189-196

Roy A, Ninan PT, Mazonson A, Pickar D, van Kammen DP, Linnoila M, Paul SM (1985): CSF monoamine metabolites in chronic schizophrenic patients who attempt suicide. Psychol Med 15:335-340

Roy A, Ågren H. Pickar D, Linnoila M, Doran A, Cutler N, Paul SM (1986): Reduced CSF concentrations of homovanillic acid and homovanillic acid to 5-hydroxyindoleacetic acid ratios in depressed patients: Relationship to suicidal behavior and dexamethasone nonsuppression. Am J Psychiatry 143:1539-1545

Roy A, De Jong J, Linnoila M (1989): Cerebrospinal fluid monoamine metabolites and suicidal behavior in depressed patients. A 5-year follow-up study. Arch Gen Psychiatry 46:609-612

Roy-Byrne P, Post RM, Rubinow DR, Linnoila M, Savard R, Davis D (1983): CSF 5HIAA and personal and family history of suicide in affectively ill patients: A negative study. Psychiatry Res 10:263-274

Scheinin M, Chang W-H, Kirk KL, Linnoila M (1983): Simultaneous determination of 3-methoxy-4-hydroxphenylglycol, 5-hydroxyindoleacetic acid, and homovanillic acid in cerebrospinal fluid with high-performance liquid chromatography using electrochemical detection. Anal Biochem 131:246-253

Secunda SK, Cross CK, Koslow S, Katz MM, Kocsis J, Maas JW, Landis H (1986a): Biochemistry and suicidal behavior in depressed patients. Biol Psychiatry 21:756-767

Shaw DM, Camps FE, Eccleston EG (1967): 5-Hydroxytryptamine in the hind-brain of depressive suicides. $\mathrm{Br}$ J Psychiatry 113:1407-1411

Spitzer RL, Williams JBW, Gibbon M, First MB (1989): 
Instruction Manual for the Structured Clinical Interview for DSM-III-R (SCID, 5/1/89 Revision). New York, Biometrics Research Department, New York State Psychiatric Institute

Spitzer RL, Endicott J (1978): Schedule for Affective Disorders and Schizophrenia (SADS), ed 3. New York: New York State Psychiatric Institute

Stanley M, Mann JJ (1983): Increased serotonin-2 binding sites in frontal cortex of suicide victims. Lancet I:214-216

Stanley M, Virgilio J, Gershon S (1982): Tritiated imipramine binding sites are decreased in the frontal cortex of suicides. Science 216:1337-1339

Stanley M, Träskman-Bendz L, Dorovini-Zis K (1985): Correlations between aminergic metabolites simultaneously obtained from human CSF and brain. Life Sci 37:12791286

Stengel E (1973): Suicide and Attempted Suicide. Harmondsworth, Middlesex, U.K.: C. Nichools \& Company Ltd

Träskman L, Åsberg M, Bertilsson L, Sjöstrand L (1981): Monoamine metabolites in CSF and suicidal behavior. Arch Gen Psychiatry 38:631-636

Träskman-Bendz L, Åsberg M, Schalling D (1986): Serotonergic function and suicidal behavior in personality disorders. Ann NY Acad Sci 487:168-174 van Praag HM (1982): Depression, suicide and the metabolism of serotonin in the brain. J Affect Disord 4:275-290

van Praag HM (1983): CSF 5-HIAA and suicide in nondepressed schizophrenics. Lancet ii:977-978

Vestergaard P, Sorensen T, Hoppe E, Rafaelsen OJ, Yates CM, Nicolaou N (1978): Biogenic amine metabolites in cerebrospinal fluid of patients with affective disorders. Acta Psychiatr Scand 58:88-96

Virkkunen M, Nuutila A, Goodwin FK, Linnoila M (1987): Cerebrospinal fluid monoamine metabolites levels in male arsonists. Arch Gen Psychiatry 44:241-247

Virkkunen M, De Jong J, Bartko J, Goodwin FK, Linnoila M (1989a): Relationship of psychobiological variables to recidivism in violent offenders and impulsive fire setters. A follow-up study. Arch Gen Psychiatry 46:600603

Virkkunen M, De Jong J, Bartko J, Linnoila M (1989b): Psychobiological concomitants of history of suicide attempts among violent offenders and impulsive fire setters. Arch Gen Psychiatry 46:604-606

Westenberg HG, Verhoeven WM (1988): CSF monoamine metabolites in patients and controls: Support for a bimodal distribution in major affective disorders. Acta Psychiatr Scand 78:541-549 